\title{
Does Language Assessment Facilitate Recent Immigrants' Participation in Canadian Society? ${ }^{1}$
}

Alister Cumming

Reviewing studies of the functions of language assessment for recent immigrants to Canada, this article suggests that a fundamental criterion-whether or not language assessment facilitates immigrants' participation in Canadian society-be used to evaluate whether assessment practices and policies are able (1) to overcome institutional or sys- temic barriers that recent immigrants may encounter, (2) to account for the range and qualities of language use that may be fundamental to specific aspects of Canadian life, and (3) to prompt majority populations and institutions to better accommodate minority populations.

Does language assessment facilitate recent immigrants' participation in Canadian society? This question forms a fundamental criterion to view, with some coherence, recent developments in government policies and educational practices in this area, despite the diversity of activities and situations they encompass and despite the absence of much public or professional discussion on this topic to date. Moreover, this criterion points toward several directions that may help to improve the conditions of language assessment for immigrant populations in Canada-directions I will review below in a way that is more selective than comprehensive, limited mainly to projects in Ontario and British Columbia, the two provinces receiving the vast majority of immigrants to English-speaking Canada.

This criterion:

1. has an ethical dimension,

2. relates directly to state and educational policies,

3. assumes a functional, systemic perspective on the processes of language assessment, and

4. is relative to the positions of different immigrant populations, their situations, and intentions.

The ethical dimension permits one to judge, empirically or impressionistically, the appropriateness or justice of language assessment practices. Does the process of language assessment help or hinder certain people trying to achieve certain things? A yes, no, or conditional "sometimes" answer is possible in regards to specific circumstances. Quite a number of recent studies in Canada have 
been asking this sort of question, some coming up with disturbingly negative answers in regards to specific situations of language assessment and others developing productive innovations to address specific problems. These ethical considerations are necessarily framed in reference to policies of the Canadian federal government that see immigration primarily as a source of labor and economic advantage for specific sectors of society, as serving newcomers' personal intentions to take up long- term residence, and as defined in reference to the official languages of English and French (Immigration Canada, 1991; Pendakur, 1992; Thomas, 1990). (Of course, ethical concerns could be raised about each of these policy assumptions, but the present paper will not attempt to do so.)

Relations of language assessment to government or educational policy have long been at issue in Canada, largely because a disjuncture exists between levels of responsibility for matters of immigration, education, and welfare-creating a persistent need for (and often failure of) various stakeholders to cooperate to coordinate services, financing, and policies (Ashworth, 1988; Burnaby, 1992; CEIAC, 1991; CSTA, 1989). Specifically, in Canada the federal government holds responsibility for immigration policy; governments in each of the ten provinces hold separate responsibilities for educational policies and funding; and local institutions, agencies, or jurisdictions like school boards or colleges typically have responsibilities for implementing language assessment and educational programs. The interests, purposes and financing formulas at each policy level tend to differ, as do the situations related to immigrant settlement throughout the country (e.g., the vast majority of immigrants with limited proficiency in the official languages of English or French settle in or around just three cities, Toronto, Vancouver, and Montreal [Pendakur \& Ledoux, 1991]). So for example, when immigration quotas are raised significantly by the federal government, as they have been in the past two years, certain provincial governments and local agencies typically require more resources to accommodate more people, though the means for doing so are seldom straightforward or easily equated across locations.

Most relevant to the present discussion has been a tendency in the past decade for decision-makers, particularly at the federal and provincial levels of responsibility, to base their considerations of language assessment on criteria related to adult immigrants' capacities to participate in Canadian life, not simply criteria of having, not having, or needing proficiency in English or French, as had been the conventional practice in previous decades. 
Consequently, government policies have promoted certain innovations for language assessment; and their effectiveness may be judged in respect to whether or not they achieve this criterion or the particular policies that correspond to it.

The functional, systemic perspective implies considering language assessment beyond its self-referential, technical criteria (such as validity, reliability, or feasibility) or practices (such as its procedures or structures of implementation), as emphasized in most discussions of language testing. Of course principled considerations of the technical dimensions of language assessment are necessary and important. But the diversity and complexity of problems associated with the situations of immigrant populations in Canada have prompted many educators and researchers recently to adopt a broader perspective, inquiring into or whether language assessment functions to facilitate people's access to and use of societal systems, such as education, work, and social services. Analyses from this perspective have yielded several promising innovations in language assessment in Canada that are worth considering more broadly.

The fourth aspect of this criterion is a relativist or pluralistic perspective. One cannot assume uniformity in language assessment in Canada, given the enormous diversity of peoples served, societal functions entailed, and circumstances under which language assessment is performed. Nothing like a single test or even common definition of language proficiency could hope to address differences between the enormous range of ethnolinguistic groups now settling in Canada (compared to just a few distinct populations from western Europe in previous decades); between certain ages or backgrounds of people seeking to enter educational systems as diverse as schools, vocational colleges or universities; or between entry into different kinds of work situations such as trades, professions, or service industries. Instead, language assessment needs to accommodate the diversity of purposes for which people may use a language as well as the backgrounds they possess and conditions in which they live. Perhaps the greatest failure of language testing in Canada in the past was the lack of a pluralistic perspective to accommodate the relation of language proficiency to societal functions. Consequently, many bodies in Canada have recognized the importance of developing language assessment that is linked directly to specific occupational or educational functions, particular cultural groups, or unique aspects of language use and tasks of settlement. 


\section{THREE PROBLEMS AND RELATED RESPONSES}

Innovations and trends in English language assessment in Canada that appear noteworthy to me-particularly in regards to the criterion of facilitating recent immigrants' participation in Canadian society-have responded to one of three related problems which had in the past limited practices for language assessment (and still may do so in many circumstances):

1. Language assessment may pose barriers to recent immigrants' participation in the institutions or systems of Canadian society. In response, certain approaches to assessment have aimed to eliminate unfair biases, to devise tests that are more appropriate to the purposes and situations of people taking language tests, or to prepare recent immigrants to cope better with barriers of language assessment they may encounter.

2. Language assessment may be too limited in scope (i.e., narrowly construed, ad hoc, or unsystematic) to reflect the range and quality of language uses that are actually fundamental to participation in Canadian society. In response, several alternative means of language assessment have been proposed, accounting more fully for the range and qualities of language use vital to participation in Canadian society.

3. Language assessment may put the burden of responsibility onto the performance of individual immigrants, neglecting the related responsibilities of majority populations and societal institutions. In response, certain innovations have tried to prompt majority populations and institutions to learn to accommodate recent immigrants better, assessing their needs and enhancing their capacities for doing so.

The nature of these problems has surfaced in a variety of studies revealing the limitations of language assessment experienced by recent immigrants to Canada. Typically, these studies have considered how language assessment functions as a point of access into or exclusion from certain societal domains or services, as a processes for streaming groups during their education, or as a cultural barrier for certain populations. At the same time, people are just now beginning to take stock of how language assessment functions within Canadian society and its educational systems.

One set of these studies has addressed immigrants' access to certain societal domains or services. For example, Cumming, Lee and Oreopoulos (1989) reviewed the practices and criteria of 
professional and trade associations in Ontario to understand reasons for the low level of representation by recent immigrants in these occupations. They found unfair, inadequate or inappropriate means for language assessment to be a basic obstacle preventing immigrants' entry into many professions or trades, along with other factors like lack of recognition for credentials or experience obtained outside of Canada. For example, tests of language proficiency for university entrance such as the TOEFL or the Michigan Test Battery were being used to judge professional accreditations for foreign-born physiotherapists, nursing assistants, or chartered accountants (Cumming, Lee \& Oreopoulos, 1989, pp. 187-221) despite these instruments bearing little information relevant to such occupations.

Likewise, Beiser (1988) assessed mental health services across Canada in view of the circumstances of recent immigrants and refugees, finding language assessment practices, along with provisions for services like interpreting, to be woefully inadequate for the needs of persons without proficiency in English or French requiring mental health treatment, particularly recent refugees. More subtle examples abound in other domains. For instance, Mellow (1992) documented circumstances surrounding a new test to certify persons to spray agricultural pesticides in B.C., which because of its language demands, proved to be an insurmountable obstacle for immigrant farm workers with limited English and literacy who already formed the majority of people employed to do this work. Similarly, St. Lawrence (1989) documented numerous barriers in the care of aged persons in Ontario lacking proficiency in English or familiarity with Canadian society, finding few means for assessing these problems or acting on them.

A second set of studies has considered the processes and long-term outcomes of particular language assessment practices in educational settings. For school-age populations, Cummins' (1984) analysis has been widely cited for its accounts of how teachers and psychologists in one school board tended to misinterpret immigrant students' language and intellectual capacities in their assessment and referral practices, leading to inappropriate and unwarranted placement in special education programs. Likewise, Ashworth (1988) showed that access to language education varied dramatically for children across Canada because of the lack of a common definition of language proficiency in English related to academic studies or means for systematically assessing it.

In regards to adult education, an ethnographic study by Belfiore and Heller (1992) revealed the subtleties and complexities of 
cultural knowledge at play in gate-keeping interviews where counselors decided on recent immigrants' eligibility for governmentsponsored language courses-subtleties and complexities which the immigrant participants seldom had much awareness of, or sufficient language proficiency to cope with. An especially problematic aspect of these interviews was a requirement that sponsorship for language courses be allocated to persons "destined for employment" and responsible for supporting a family (a qualification that has recently been removed). Of course this criterion tended to be sexist-favouring male rather than female spouses-and it may in part be responsible for demographic figures showing the number of females with limited English to be nearly double that of males in Canada (Boyd, 1992; Cumming, 1991; Doherty, 1992). In other instances, blatantly inappropriate uses of tests have been documented, e.g., of tests designed for children or for mother-tongue Basic Education being used to place adults with limited English into ESL programs, lack of local norm-references to interpret test scores appropriately in relation to local populations (Cumming, 1991, p. 89).

A third set of studies has showed the inadequacy of conventional language assessment and educational practices for specific immigrant groups in Canada. Several detailed ethnographic studies have revealed that conventional norms and expectations for adult language education in Canada tend to be unsuitable for, if not utterly irrelevant to, the life experiences of such distinct populations as: Mayan refugees settling in Canada to escape persecution in $\mathrm{El}$ Salvador or Guatemala (Giltrow \& Colhoun, 1989); Hispanophone immigrants to Canada with low levels of prior education (Klassen, 1992); or women from the Indian state of the Punjab settling in Canada to marry Canadian husbands of similar backgrounds (Cumming \& Gill, 1992). A common finding in these studies is that typical practices to assess language proficiency, learners' progress in language courses, or functional uses of English for daily life appear inappropriate (or even bizarre) if viewed from the perspective of these immigrants themselves, their personal experiences and goals and their cultural backgrounds. For example, Derwing (1992) explains how language tests to obtain Canadian citizenship boil down to demonstrating knowledge of grammatical tenses in English or French and a few historical or geographical details, rather than evaluating any principled criteria that define what citizenship may actually entail or require.

A fourth set of studies has looked at the functions of language assessment within specific institutions, finding biases against recent immigrant populations and a lack of appropriate accommodations 
by majority populations or institutions. This perspective has become hotly topical in urban centers such as Toronto or Vancouver as so-called minorities (i.e., with mother tongues other than English) have recently come to form the numerical majority in many schools and other settings, raising fundamental questions about the language norms and standards guiding language assessment and educational programs. (McAndrew, 1993, outlines how these complexities have been even more severe within the competing tensions of French, English, and minority language cultures in Montreal schools.) At a micro-level, it has long been evident that certain cultural biases commonly appear in academic tests in Canadian schools, disadvantaging recent immigrants who may be unfamiliar with local cultural references, allusions, or schemata (Mohan, 1986, pp. 122-135). Indeed, Klesmer (1993) has demonstrated precisely that in one Toronto-area school board, 12-year-old, immigrant students with mother tongues other than English tend to take four to six years to achieve local norms on many standardized tests commonly used in schools-suggesting that unique achievement criteria need to be developed for this population.

At a macro-level, analyses such as Cummins (1988) and Elson (1992) argue that Canadian institutions like schools and universities (respectively) have to move beyond a simple reliance on language tests to exclude or disadvantage persons without requisite proficiency in English-to a position where they adopt general policies that address diverse needs for English language education across curricula and institutions, including accreditation of courses in ESL, teacher and faculty orientation, and systems to promote cultural equity and recognition of ethnic differences. A common, recent theme among educators in Canada has been the need for majority populations and institutions to accommodate recent immigrant students better. The needs for doing so are increasingly great (Lewis, 1992), but the means by which this might be done are seldom easily agreed upon. For example, one major initiative in this direction, documented in Cummins (1989), became a point of considerable public controversy: The Toronto Board of Education adopted a policy to integrate heritage language instruction (i.e., education in languages other than English or French) into regular school programs, a policy that was bitterly opposed by teacher federations and other interest groups, then finally abandoned (although such programs do continue after school hours and on weekends). 
Given these controversies it is perhaps surprising that only in the past few years have surveys been undertaken to describe ESL education in Canada systematically, or the place of language assessment within such systems. So I must couch the list of criticisms about language assessment above with the qualification that no one really has a very clear idea overall of what language assessment is doing for (or with) recent immigrant populations in Canada. The two English-speaking provinces receiving large numbers of immigrants have just recently undertaken their first descriptive surveys of ESL education systems, respectively, for adults in B.C. (Cumming, 1991) and for schools in Ontario (Cumming, Hart, Corson \& Cummins, 1993). Two recent national surveys of school ESL programs (CSTA, 1989) and government-sponsored adult ESL courses (CEIAC, 1991) focused almost entirely on "head counts" of people in ESL programs, estimating costs of programs, and itemizing controversial issues-but scarcely touching on issues of language assessment or curricula. Prospects to consider these issues on a truly global level appear through IEA's upcoming comparative study of language education to be conducted in about 30 countries (IEA, 1993), but it is not clear at this time how many Canadian provinces are willing to fund the costs of participating in systematic, broad-scale evaluation research into their secondlanguage programs.

\section{RESPONSES TO THE BARRIER PROBLEM}

Two distinct responses have emerged to the problem of language assessment posing barriers to recent immigrants in Canada. Both initiatives involve systems for orientation to initial processes of language assessment and societal adaptation as well as personalized, detailed, competency-based evaluations of language proficiency.

For adult immigrants, the federal government started in 1991 to implement a new program of funded language training for adult immigrants, LINC (Language Instruction for New Canadians), replacing earlier programs such as the Canadian Jobs Strategy, Settlement Language Training Program, and Citizenship Instruction and Language Textbook Agreement. Language assessment has formed a major emphasis of the new program, along with various orientation materials given to persons granted immigrant status. The language assessment procedures, called A-LINC (Tegenfeldt \& Monk, 1992), involve an individual oral interview then seven thematically-related tasks adapted on-site to the immigrant client's work preferences and previous experiences, such as introducing oneself, 
filling out forms, indicating work preferences in reference to photograph prompts, a writing task, and a reading-paraphrase task. A person's language performance is rated according to five descriptive criteria, three of which define levels for ESL instruction in LINC programs, and the other two define levels of competency in English beyond eligibility for the program. Although using a standard assessment format, each region of the country has taken different approaches to orienting people to options they may be eligible for upon completion of the assessment. Efforts are reportedly made to suit immigrant clients, rather than institutional programs (as had been the practice in the past), e.g., in B.C., clients are shown a map of their local area then given cards describing options they may choose for training such as types of facilities, transportation, or child care services.

After three years of developing the instrument and two years of training assessors in all parts of the country, A-LINC is now functioning as a nation-wide system to place immigrants with limited proficiency in English into basic ESL programs at colleges, school board continuing education programs, and various immigrant-serving agencies. Work at present is now concentrating on defining a set of benchmarks that will indicate when learners have achieved requisite levels of English proficiency (e.g., to exit from LINC programs) as well as to account for individual differences, such as mother-tongue literacy (Taborek, 1993). This approach to assessment follows directly from the stated, intended policies of the federal government to:

significantly increase the number of language training opportunities available to immigrants; provide immigrants with more flexible training options to fit their individual needs and circumstances; achieve a better match between the training offered and individual needs through improved assessment and referrals; ensure that more immigrants receive timely assistance during the early stages of their settlement in Canada; make language training available to a broader range of immigrants, regardless of their immigrant category or their labor market status or intentions; and increase the proportion of newly arrived adult immigrants receiving language training from the 1990 level of about 28 per cent to about 45 per cent in 1995. (Immigration Canada, 1991, p. 7, italics in original).

Nonetheless, despite these worthy goals, many concerns still persist about whether the LINC program has been able to achieve 
these aims fully or equitably; whether the approach to assessment can (or even should) be implemented uniformly across diverse sites, agencies, and situations; and whether the assessment procedures function merely to group immigrants within LINC programs rather than to help facilitate their participation in Canadian society more broadly (e.g., see OCASI, 1991).

For school-age learners in many urban settings, needs for orientation and language assessment have recently come to be situated in reception centres, i.e., a designated school site that specializes in accommodating students who are recent immigrants to Canada by placing students in appropriate schools throughout a school district, providing initial periods of ESL instruction, and assisting in settlement and orientation. The structures, facilities and practices of these reception centres vary considerably, given that they are administered locally rather than nationally. Nonetheless, language assessment at these centres is typically extensive and individualized, involving interviews and consultations with families and interpreters, long-term observation by ESL teachers, and administration of diverse tests. Despite the proliferation of reception centres in many parts of Canada in the past decade, their underlying premises and long-term impacts have recently been questioned by advocates of a "whole school philosophy" (becoming increasingly popular in central Ontario), who suggest that reception centres create environments that are structurally isolated from the societal processes and factors that immigrant learners actually need to participate in, prompting the criticism that they may function as "holding tanks" or "ghetto-like environments" rather than immediate facilitators of societal integration (e.g., see Cumming, Hart, Corson \& Cummins, 1993, pp. 28-29). Advocates of a "whole school philosophy" instead urge individual schools to accept responsibilities for assessment and education of immigrant students by developing local support and administrative structures to serve these students within their own communities and neighborhoods.

\section{RESPONSES TO THE LIMTTED SCOPE OF LANGUAGE ASSESSMENT}

Apart from the innovations in LINC and reception centres described above, two responses have appeared to problems in the limited scope of language assessment. One response has been to seek alternative, broad-based criteria for language assessment, i.e., beyond those normally available within the limited format of a test 
or interview. A second response has been to devise performance tests for specific purposes.

Two examples of alternative, broad-based criteria for language assessment appear in research studies of specific immigrant populations, assessing their functional uses of English for settling in particular locations in Canada. Mastai (1980) studied Israeli adults settling in Vancouver, suggesting that their processes of settlement could be viewed as a common set of adaptation tasks, such as finding housing, schools, and employment or learning new systems for personal financing, transportation, and personal interaction. She devised a preliminary list of these tasks, based on interviews with a sample population, then validated priorities and ratings of difficulty for each task for a different population through $q$-sort methodologies, determining that "finding a meaningful job" was overwhelmingly judged to be the most important but most difficult adaptation task. A different approach was taken by Cumming and Gill (1991) who studied Punjabi-background women in Vancouver participating in an innovative ESL program. The study used standard interview schedules to document the women's routine uses of Punjabi and English in their daily lives, finding the women increased (over a ten-month period) their frequency of using English to read, talk on the telephone, and communicate with their children's schools (from about once per month to almost daily) while many of their other societal functions remained consistent in Punjabi. Both of these approaches provide long-term, functional perspectives on language use and settlement processes that could not be obtained by conventional language tests.

One carefully-documented study to develop language proficiency assessment for a specific purpose is described in Wesche's (1987) account of the Ontario Test of English as a Second Language, devised for immigrant and non-Canadian students in undergraduate programs at universities in Ontario. Rather than attempting to ascertain a general score of language proficiency, this test evaluates students' performance on representative academic tasks in their subject disciplines. Other developments in professionally-oriented performance testing in Canada, however, have mainly catered to majority populations learning one of the official languages (i.e., Anglophones learning French or Francophones learning English), for example, for specific jobs in the public service, rather than to recent immigrants. 


\section{RESPONSES BY MAJORITY POPULATIONS}

Three projects have recently made notable efforts to prompt Canadian majority populations to accommodate recent immigrants, pointing the way toward directions that expand our consideration of language assessment beyond the testing of individual language learners' proficiency in English.

The first and most comprehensive of these projects is the Toronto Board of Education's Benchmarks (Larter, n.d.; Larter, 1993; Toronto Board, 1991), a set of over 100 tasks and holistic descriptions of students' performance at different achievement levels in English language and mathematics at grades three, six and eight, accompanied by print and video materials for use by teachers, families, and others. Though not aimed at immigrant students, these benchmarks serve the function of making explicit the normative criteria and standards of performance that teachers and assessors have applied to judge samples of students' reading, writing, and other language tasks-in a context where the majority school population is composed of students whose mother tongue is not English. For example, five levels of performance are described in detail on each integrated communication task, documenting the percentage of students typically achieving each performance level, e.g., top $14 \%$, next $22 \%$, middle $27 \%$, next $28 \%$, and bottom $9 \%$. In this way, explicit information is made accessible to students, teachers, and families concerning the qualities of language performance that immigrant and other students may aim for in representative school tasks. Moreover, these tasks form an integral part of the school curricula, a step facilitated by the involvement of teachers and recently-retired teachers in the development and validation of these benchmarks, rather than imposition by external evaluators or government officials. Various other school boards across Canada are now adopting this approach.

A second innovative program has helped secondary school students and their teachers across Canada to develop leadership skills in multicultural awareness and anti-racist behavior. Groups of about 25 students and their teachers from one school are paired with students and teachers in a different region of Canada, spending one week at both locations to learn about cultural differences, concepts of prejudice and discrimination, problems of recent immigrants or aboriginal populations, then to formulate action plans to implement in their schools and communities, such as anti-racist policies or multicultural clubs. Schools participating in the program have typically been in medium-sized cities or suburbs 
that are just beginning to experience demographic shifts toward cultural diversity, while participating students have tended to be from both minority and majority backgrounds. A three-year evaluation study of the program found these exchanges to promote significantly students' awareness of their own biases and prejudices as well as capacities to identify causes of prejudice, identify barriers between people, and use language related to race and culture (Cumming \& Mackay, 1993)-perceptions which in the long-term may help to change the values underlying teachers' and students' informal assessments of immigrant students' language.

A third perspective appears in several assessments of communications needs in small businesses conducted by the Open Learning Agency in the greater Vancouver area (Tracy Defoe, personal communications, 1991). A typical scenario in these settings is that a business requests special purpose language courses for their employees with limited proficiency in English. However, systematic needs analyses within the business settings often demonstrate that the source of such perceived problems arise because of deficiencies in the overall communications systems within the work environment (e.g., unclear instructions or designations of responsibilities as established by English-dominant workers), rather than because of immigrants' limited English. Accordingly, educational programs are designed to help majority-background and minority-background workers communicate with each other within these settings, an approach that has reportedly satisfied employers and employees alike, rather than assuming that immigrant workers alone must adapt their communication skills.

\section{SUMMARY: ADEQUACY OF THESE RESPONSES}

The innovative responses documented here are suggestive of directions worth taking to current problems in the assessment of immigrants' language. But it could hardly be said that any one of the innovations alone has fully achieved the criterion of facilitating immigrants' participation in Canadian society. To attain that goal, considerably more developmental work is required at all levels and in all areas of the country. Moreover, detailed empirical studies are vital to informing such developments including, for example, longitudinal analyses (e.g., to trace how people actually use language to fulfill purposes of settlement and to determine how they get better at doing so); controlled experiments (e.g., comparing representative groups of immigrants participating in specific ESL programs compared to equivalent groups that are not); ethnographic 
studies (e.g., describing how language uses function in various societal domains important to settlement and how these can be taught and learned); participatory action research (e.g., helping specific populations now poorly served by language education to develop culturally-appropriate, viable programs); and research into and about the nature of language assessment itself (e.g., adopting more than just a technical perspective on the reliability and validity of instruments-to inquire into the systemic and institutional functions of language assessment as suggested in the present article).

What does emerge from the present analysis, however, is the conclusion that current developments in language assessment in Canada need to cover a spectrum of perspectives that move from consideration of immigrants' (1) initial settlement in Canada and entry into ESL programs to their (2) long-term processes of accommodation to Canadian society, as well as (3) long-term adjustments that have to be made by majority populations. At this time, most approaches to language assessment only appear to be addressing one of these three processes-primarily the first, screening function. (For example, Cumming, Hart, Corson and Cummins' (1993) comprehensive survey of Ontario school boards found most boards in the province to have specific policies and procedures for assessing students' entry into school ESL, ESD and mother-tongue French programs, but no boards to have comparable criteria for monitoring students' progress through or exit from such programs, apart from individual teachers' judgments.) All three processes, however, need to be developed to establish systems of language assessment that are ethically justifiable, relate directly to state and educational policies for immigration, account for the systemic functions of language assessment in society and education, and are relative to the positions of different immigrant populations, their situations, and intentions.

Current innovations, as noteworthy as each is, only offer partial solutions to current problems. For example, responses to the barrier problem have mainly addressed the entry of recent immigrants into Canadian society or certain educational programs. In turn, recent responses to immigrants' long-term adaptation to Canadian society or the majority society's accommodation of recent immigrants have started to address limitations in the scope of language assessment or majority responsibilities. But all current innovations along these lines have been visibly restricted in their perspectives, for example, to a few specific settings or populations, to requirements for resources and efforts that may prove too costly to be feasible for 
widespread adoption (or even possible to implement on an equivalent basis in city and rural or prosperous and financially-deprived environments alike), or to reliance on the willingness of majority populations to make significant changes in their positions of power and authority. However, if language assessment is to achieve the goal of helping to facilitate immigrants' participation in Canadian society-as many people are now suggesting it do-much remains to be done in all of these directions.

\section{NOTE}

1. This paper was initially prepared for the Colloquium on Testing and Assessment of Immigrants' Language at the International Association of Applied Linguistics' Convention, August 10, 1993 in Amsterdam, where parallel presentations were made in reference to Australia, Israel, and the United States. I thank Helen Tegenfeldt, Tracy Defoe, Elana Shohamy and several TESL Canada Journal reviewers for comments that helped to shape the paper.

\section{THE AUTHOR}

Alister Cumming is Head of the Modern Language Centre and Associate Professor of Curriculum at the Ontario Institute for Studies in Education. His research focuses on writing in second languages, curriculum evaluation, and thinking processes in ESL instruction and learning.

\section{REFERENCES}

Ashworth, M. (1988). Blessed with bilingual brains: Education of immigrant children with English as a second language. Vancouver: Pacific Educational Press.

Beiser, M. (1988). After the door has opened: Mental health issues affecting immigrants and refugees in Canada. Ottawa: Secretary of State, Multiculturalism; Health \& Welfare Canada.

Belfiore, M. \& Heller, M. (1992). Cross-cultural interviews: Participation and decision-making. In B. Burnaby \& A. Cumming (Eds.), Socio-political aspects of ESL in Canada (pp. 223-240). Toronto: OISE Press.

Boyd, M. (1992). Immigrant women: Language, socio-economic inequalities, and policy issues. In B. Burnaby \& A Cumming (Eds.), Socio-political aspects of ESL in Canada (pp. 141-159). Toronto: OISE Press. 
Burnaby, B. (1992). Coordinating settlement services: Why is it so difficult? In B. Burnaby \& A. Cumming (Eds.), Socio-political aspects of ESL in Canada (pp. 122-137). Toronto: OISE Press.

Canada Employment and Immigration Advisory Council (CEIAC). (1991). Immigrants and language training. Ottawa: Employment and Immigration Canada. Report presented to the Minister of Employment and Immigration.

Canadian School Trustees' Association (CSTA). (1989). Scholastic adaptation and cost effectiveness of programs for immigrantirefugee children in Canadian schools. Ottawa: Author.

Cumming, A. (1991). Identification of current needs and issues related to adult ESL instruction in British Columbia. Richmond, B.C.: Open Learning Agency. ERIC ED 353855.

Cumming, A \& Gill, J. (1991). Learning ESL literacy among Indo-Canadian women. Language, Culture and Curriculum, 4, 181-200.

Cumming, A \& Gill, J. (1992). Motivation or accessibility? Factors permitting Indo-Canadian women to pursue ESL literacy instruction. In B. Burnaby \& A. Cumming (Eds.), Socio-political aspects of ESL in Canada. (pp. 241-252). Toronto: OISE Press.

Cumming, A., Hart, D., Corson, D. \& Cummins, J. (1993). Provisions and demands for English as a Second Language, English Skills Development, and Actualisation Linguistique in Français in Ontario. Report submitted to the Ontario Ministry of Education and Training. Toronto: Modern Language Centre, Ontario Institute for Studies in Education. ONTERIS.

Cumming, A. \& Mackay, R. (1993). SEVEC's multicultural/anti-racist leadership exchange program: Final evaluation report. Ottawa: Society for Educational Visits and Exchanges in Canada. ONTERIS.

Cumming, P., Lee, E. \& Oreopoulos, D. (1989). Access: Task force on access to professions and trades in Ontario. Toronto: Ontario Ministry of Citizenship.

Cummins, J. (1984). Bilingualism and special education: Issues in assessment and pedagogy. Clevedon, Avon: Multilingual Matters.

Cummins, J. (1988). From multicultural to anti-racist education: An analysis of programmes and policies in Ontario. In T. Skutnabb-Kangas \& J. Cummins (Eds.), Minority education: From shame to struggle (pp. 127-157). Clevedon, Avon: Multilingual Matters.

Cummins, J. (1989). Heritage language teaching and the ESL student: Fact and friction. In J. Esling (Ed.), Multicultural education and policy: ESL in the 1990s (pp. 3-17). Toronto: OISE Press.

Denwing, T. (1992). Instilling a passive voice: Citizenship instruction in Canada. In B. Burnaby \& A Cumming (Eds.), Socio-political aspects of ESL in Canada (pp. 193-202). Toronto: OISE Press.

Doherty, N. (1992). Challenging systemic racism in the National Language Training Program. In B. Burnaby \& A Cumming (Eds.), Socio-political aspects of ESL in Canada (pp. 67-76). Toronto: OISE Press.

Elson, N. (1992). The failure of tests: Language tests and post-secondary admissions of ESL students. In B. Burnaby \& A. Cumming (Eds.), Socio-political aspects of ESL in Canada (pp. 110-121). Toronto: OISE Press.

Giltrow, J. \& Colhoun, E. (1989). Attitudes toward language acquisition among MesoAmerican refugees: Programmes for self-teaching. Bulletin of the Canadian Association of Applied Linguistics, 11, 57-71. 
International Association for the Evaluation of Educational Achievement (IEA). (1993). The IEA Language Education Study. Draft proposal. The Hague: International Association for the Evaluation of Educational Achievement.

Immigration Canada. (1991). Annual report to parliament, immigration plan for 1991-1995, year two. Ottawa: Employment and Immigration Canada.

Klassen, C. (1992). Obstacles to learning: The account of low-education Latin American adults. In B. Burnaby \& A. Cumming (Eds.), Socio-political aspects of ESL in Canada (pp. 253-264). Toronto: OISE Press.

Klesmer, H. (1993). ESL achievement project: Development of English as a second language achievement criteria as a function of age and length of residence in Canada. North York, Ontario: North York Board of Education.

Larter, S. (n.d.). Benchmarks. Toronto: Toronto Board of Education.

Larter, S. (1993). Demystifying the goals of education: Toronto's benchmark program. Orbit, 24, 2, 22-24.

Lewis, S. (1992). Report on race relations in Ontario. Toronto: Publications Ontario.

Mastai, J. (1980). Adaptation tasks of Israeli immigrants to Vancouver. Unpublished doctoral dissertation, University of British Columbia.

McAndrew, M. (1993). The integration of ethnic minority students fifteen years after Bill 101: Some issues confronting Montreal's French language public schools. Unpublished manuscript. Universite de Montreal: Centre d'Etudes Ethniques.

Mellow, J. D. (1992). A case study of rural second-language education: Barriers to adult settlement and education. In B. Burnaby \& A. Cumming (Eds.), Socio-political aspects of ESL in Canada (pp. 292-303). Toronto: OISE Press.

Mohan, B. (1986). Language and content. Reading, MA: Addison-Wesley.

Ontario Council of Agencies Serving Immigrants (OCASI). (March, 1993). Repont on the findings of the OCASI LINC questionnaire. Toronto: Ontario Council of Agencies Serving Immigrants.

Pendakur, R. (1992). Labor market segmentation theories and the place of immigrants speaking neither English nor French in Canada. In B. Burnaby \& $\mathbf{A}$ Cumming (Eds.), Socio-political aspects of ESL in Canada (pp. 160-181). Toronto: OISE Press.

Pendakur, R. \& Ledoux, M. (1991). Immigrants unable to speak English or French: A graphic overview. Ottawa: Secretary of State of Canada, Policy and Research, Multiculturalism Sector.

St. Lawrence, I. (1989). Aging together: An exploration of attitudes towards aging in multicultural Ontario. Toronto: Ontario Advisory Council on Senior Citizens.

Taborek, E. (1993). The national working group on language benchmarks. TESL Toronto Newsletter, fall-winter 93-94, 10-11.

Tegenfeldt, H. \& Monk, V. (1992). Assessment interview: Language instruction for newcomers to Canada. Vancouver: Vancouver Community College.

Thomas, D. (1990). Immigrant integration and the Canadian identity. Ottawa: Employment and Immigration Canada.

Toronto Board of Education. (1991). Fact sheet 6: Benchmarks. Toronto: Toronto Board of Education.

Wesche, M. (1987). Second language performance testing: The Ontario Test of ESL as an example. Language Testing, 4, 28-47.

TESL CANADA JOURNAL/REVUE TESL DU CANADA 